\title{
Prática de conflitos sociopedagógicos em sala de Recursos Multifuncional para Altas Habilidades/Superdotação
}

\author{
Practice of sociopedagogical conflicts in a Multifunctional Resource Room for \\ High Ability/Giftdness
}

\section{Práctica de conflictos sociopedagógicos en el Aula de Recursos Multifuncionales para Altas Capacidades/Superdotación}

\author{
Bernadete de Fatima Bastos Valentim \\ Professora doutora da Universidade Estadual do Centro-Oeste, Guarapuava, PR, Brasil \\ E-mail: bernadetevalentim@unicentro.br ORCID: https://orcid.org/0000-0002-2521-6540 \\ Carla Luciane Blum Vestena \\ Professora doutora da Universidade Estadual do Centro-Oeste, Guarapuava, PR, Brasil \\ E-mail: cvestena@unicentro.br ORCID: https://orcid.org/0000-0002-8655-7840
}

Recebido em 08 de agosto de 2021

Aprovado em 24 de setembro de 2021

Publicado em 27 de dezembro de 2021

\section{RESUMO}

Estudantes com Altas Habilidades/Superdotação (AH/SD), são reconhecidos pelos comportamentos diferenciados relacionados à habilidade acima da média, criatividade e envolvimento com a tarefa. Considerando a necessidade de promover a interação social entre eles, o objetivo deste artigo é analisar uma prática de discussão de conflitos sociopedagógicos, realizada com estudantes que têm AH/SD, na sala de recursos multifuncional. Trata-se de uma pesquisa exploratória desenvolvida por meio de uma proposta de intervenção, baseada em conflitos sociopedagógicos, a partir da teoria piagetiana. As participantes foram duas estudantes com AH/SD, matriculadas na sala de recursos multifuncionais para Altas Habilidades/Superdotação dos anos finais do Ensino Fundamental. Os resultados demonstraram que a discussão de conflitos sociopedagógicos promoveu o envolvimento e a interação entre os estudantes. $O$ estudo concluiu que é fundamental desenvolver práticas pedagógicas voltadas para a interação social dos estudantes por meio de ambientes cooperativos em que os estudantes com AH/SD possam ser agentes ativos, trazendo os seus conflitos para serem discutidos em sala de aula e construindo com eles interação social de qualidade.

Palavras-chave: Altas Habilidades/Superdotação; Ambiente cooperativo; Piaget.

\section{ABSTRACT}

Students with High Ability/Giftdness, are recognized by differentiated behaviors related to above average ability, creativity, and involvement with the task. Considering the need to promote social interaction, the aim of this article is to analyze a practice of socio-educational conflict discussion, carried out with students who have High Ability/Giftdness, in the multipurpose resource room. Ability/Giftdness in the multipurpose resource room, in order 
to promote social interaction. This is exploratory research developed through an intervention proposal, based on socio-pedagogical conflicts, from the Piagetian theory. The participants were two students with High Ability/Giftdness, enrolled in the multipurpose resource room for high abilities/super ability and, final years of elementary school. The results showed that, the discussion of socio-pedagogical conflicts, promoted the involvement and interaction among students. The study concluded that it is essential to develop pedagogical practices aimed at the social interaction of students with High Ability/Giftdness can be active agents, bringing their conflicts to be discussed in the classroom and building with them, quality social interaction.

Keywords: High Ability/Giftdness; Cooperative environment; Piaget.

\section{RESUMEN}

Los alumnos con altas capacidades/superdotación, se reconocen por los comportamientos diferenciados relacionados con la capacidad superior a la media, la creatividad y la implicación con la tarea. Teniendo en cuenta la necesidad de promover la interacción social, el objetivo de este artículo es analizar una práctica de discusión de conflictos socioeducativos, realizada con alumnos que tienen altas capacidades/superdotación, en el aula de recursos polivalente. Se trata de una investigación exploratoria desarrollada a través de una propuesta de intervención, basada en los conflictos socio-pedagógicos, desde la teoría piagetiana. Los participantes fueron du alumnos con altas capacidades/superdotación, matriculados en el aula de recursos polivalentes para altas capacidades/superdotación y, últimos cursos de primaria. Los resultados mostraron que, la discusión de los conflictos socio-pedagógicos, promovió la participación y la interacción entre los estudiantes. El estudio concluye que es fundamental desarrollar prácticas pedagógicas dirigidas a la interacción social de los alumnos a través de entornos cooperativos en los que los alumnos con altas capacidades/superdotación puedan ser agentes activos, aportando sus conflictos para ser discutidos en el aula, y construyendo con ellos, una interacción social de calidad.

Palabras clave: Altas Capacidades/Superdotación; entorno cooperativo; Piaget.

\section{Introdução}

As Altas Habilidades/Superdotação (AH/SD) têm sido reconhecidas pelos comportamentos diferenciados, nos quais incluem-se a habilidade acima da média, a criatividade, e o envolvimento com a tarefa, de acordo com a Teoria dos Três Anéis, de Renzulli (2004, 2014). Essas características são observadas em diversas áreas, seja na capacidade intelectual geral; na aptidão acadêmica específica; no pensamento produtivocriativo; na capacidade de liderança; no talento especial para Artes, ou na capacidade psicomotora. (VIRGOLIM, 2019). 
http://dx.doi.org/10.5902/1984686X67108

Essa definição tem relevância no sentido de reconhecer que as AH/SD podem ser reconhecidas para além da aptidão acadêmica e intelectual. Essa nomenclatura é adotada no contexto educacional brasileiro, em documentos oficiais, e pelo ConBrasD (Conselho Brasileiro para a Superdotação). Reconhecer as Altas Habilidades em diversas áreas, também contribui para a superação do mito de que pessoas com AH/SD precisam ser boas em todas as áreas. É preciso compreender, por exemplo, que podem demonstrar habilidade superior em uma área e estar no limite em outras.

Vale ressaltar que, os estudantes com AH/SD fazem parte do público da Educação Especial, portanto, têm direito ao AEE (atendimento educacional especializado). (BRASIL, 2010). Esse atendimento pode ser ofertado no contraturno escolar, em salas de recursos multifuncionais, ou em centros especializados de atendimento, onde irá desenvolver projetos de pesquisa com temáticas que sejam do interesse de cada um.

Eles também têm direito ao enriquecimento curricular, realizado na sala de aula comum. Esse pode ser feito de modo intracurricular ou extracurricular, como destaca Valentim (2019, p. 47):

[...] o professor pode aprofundar o conteúdo por meio de atividades desafiadoras, de propostas de pesquisas, de disponibilização de questões com grau maior de complexidade, de atividades em grupo, entre outras. $\mathrm{O}$ enriquecimento extracurricular pode ser proporcionado na sala de recursos multifuncionais ou em núcleos de atividades, ao propor projetos de trabalhos individuais ou coletivos, de acordo com a área de interesse de cada estudante.

Todos os serviços de AEE fazem parte da conquista do direito, e advém do grande movimento das pesquisas e das lutas do Conselho Brasileiro para Superdotação, das diversas associações existentes Brasil afora de pais de crianças e adolescentes com AH/SD. São esses movimentos que fortalecem as linhas de pesquisas, bem como 0 engajamento nas investigações nas AH/SD.

As pesquisas em AH/SD têm aumentado gradativa e significativamente no decorrer dos tempos. Inúmeras pesquisas têm sido desenvolvidas tanto no cenário nacional, quanto internacional, abordando temas como a identificação, o atendimento, as políticas e a formação de professores, dentre outros específicos. (HEUSER; WANG; SHAHID, 2017; MARTINS; CHACON; ALMEIDA, 2018; MARTINS et. al., 2016; MCCLAIN; PFEIFFER, 2012; NAKANO; SIQUEIRA, 2012; PÉREZ; FREITAS, 2011; SUMIDA, 2013).

Martins et al. (2016) aponta que entre os anos de 1987 e 2014, o tema da identificação, do atendimento e questões relacionadas a identidade da pessoa com 
http://dx.doi.org/10.5902/1984686X67108

$A H / S D$, estão entre os mais pesquisados. No escopo das pesquisas, não se percebe frequência em temas relacionados a interação social, tampouco se encontram estudos sobre os conflitos sociopedagógicos em estudantes com $\mathrm{AH} / \mathrm{SD}$, pelos quais passam constantemente.

Conflitos sociopedagógicos são conflitos que ocorrem na sala de aula, entre colegas ou professores, sobre os mais diversos assuntos e situações que nela são desencadeados. Podem estar relacionados ao conteúdo que está sendo abordado, sobre o encaminhamento dado na aula, ou até mesmo pela manifestação de um posicionamento crítico do estudante com AH/SD que não tenha sido compreendido por seus colegas ou professores, gerando, assim, o conflito. (VALENTIM; VESTENA, 2019).

A resolução desses conflitos sociopedagógicos contribui para uma tomada de consciência no âmbito social, sobre o reconhecimento da importância dos relacionamentos com o outro (PIAGET, 1977b). O conflito tem efeito pedagógico (VINHA, 2013), mas para isso, é preciso permiti-lo e compreendê-lo dessa forma, para que resulte em tomada de consciência no âmbito social. Vale destacar que

$\mathrm{Na}$ escola podemos aproveitar os conflitos de "quereres" para favorecer o autoconhecimento, a identificação dos afetos que os movem, a análise das consequências de suas escolhas e atitudes e o desenvolvimento dos mecanismos de regulação desses afetos. (VINHA, 2013, p. 75).

Considera-se, pois, relevante as pesquisas que abordem a resolução de conflitos e, sobretudo, a necessidade de se oferecer aos estudantes com AH/SD, atendidos em sala de recursos multifuncional, uma proposta de intervenção baseada em resolução de conflitos sociopedagógicos, que os auxiliem a desenvolver esse reconhecimento do outro, bem como a importância da interação social com os seus pares.

A partir da perspectiva de escassas pesquisas que abordem a discussão de conflitos sociopedagógicos com estudantes que têm $\mathrm{AH} / \mathrm{SD}$, e da necessidade de proporcioná-los práticas pedagógicas integrativas, propusemos a seguinte questão de investigação: a resolução de conflitos sociopedagógicos pode promover a interação social em estudantes que têm $\mathrm{AH} / \mathrm{SD}$ ?

Tal trabalho de investigação se justifica por contribuir com pesquisadores, professores e pais, apontando para a importância da interação social na Superdotação, e que essa dimensão precisa ser considerada no contexto escolar e implementada nas propostas pedagógicas das salas de atendimento educacional especializadas. Vale destacar também, que, nesse artigo serão apresentados os dados provenientes de dois encontros, produzidos 
http://dx.doi.org/10.5902/1984686X67108

por duas participantes. Optou-se em fazer um recorte da pesquisa de doutorado realizada com sete estudantes com AH/SD durante nove encontros.

O objetivo do artigo foi analisar uma prática de discussão de conflitos sociopedagógicos, realizada com estudantes que têm $\mathrm{AH} / \mathrm{SD}$, e que estão inseridos na sala de recursos multifuncional.

\section{Metodologia}

Foi realizada uma pesquisa qualitativa exploratória pois, se deteve no processo e não no produto, e buscou compreender e analisar dados a partir da interpretação da realidade investigada (TRIVIÑOS, 2011). É importante referir ainda, que no percurso da pesquisa houve grande preocupação com os acontecimentos reais, e isso vai ao encontro do dito por Gerhardt e Silveira (2009, p. 32), no sentido de que a pesquisa qualitativa "[...] preocupase, portanto, com aspectos da realidade que não podem ser quantificados, centrando-se na compreensão e explicação da dinâmica das relações sociais."

Devido a sua configuração de intervenção e seu propósito de provocar mudanças no meio em que foi realizada, a pesquisa se caracterizou como pesquisa-ação. A pesquisaação é,

[...] uma ação que visa a mudanças na realidade concreta com uma participação social efetiva, a pesquisa-ação crítica está centrada no agir, através de uma metodologia exploratória, tendo seus objetivos definidos no campo de atuação pelo pesquisador e pelos participantes. Seus resultados estão vinculados à tomada de consciência dos fatores envolvidos nas situações de vida imediata e na participação coletiva para a mudança da ordem social. (ROCHA; AGUIAR, 2003, p. 65).

Vale destacar que, desde a sua concepção até a execução, a proposta de pesquisa realizada por meio da intervenção não visou apenas uma produção de dados, visou provocar alguma mudança nos estudantes com AH/SD, na promoção de um espaço colaborativo de discussões sobre os conflitos sociopedagógicos por eles vivenciados.

O campo de pesquisa foi a sala de recursos multifuncional de uma escola pública do interior do Estado do Paraná. A pesquisa seguiu os procedimentos éticos, foi autorizada pela Secretaria de Estado de Educação, bem como pelo Núcleo Regional de Educação e da equipe gestora do colégio em questão. Esse projeto foi aprovado pelo parecer número 2.451.548 em reunião de 20/12/2017, e foi realizado em Guarapuava, no período de fevereiro de 2018 a dezembro de 2019. A pesquisa foi apresentada à professora e aos pais das estudantes, os quais autorizaram a sua participação. 
http://dx.doi.org/10.5902/1984686X67108

Após a apresentação da pesquisa, foram realizadas observações e encontros de intervenção com as estudantes, dos quais a professora responsável pela turma se fez presente, porém, sem interferir na dinâmica da pesquisa. Em cada encontro os passos percorridos seguiram a mesma ordem.

O primeiro passo foi a apresentação do conflito mediante a leitura; o segundo passo foi a certificação de que haviam compreendido o conteúdo do conflito; o terceiro passo foi solicitar que escrevessem as respostas no instrumento elaborado pelas pesquisadoras, e o quarto passo foi o compartilhamento e discussão das respostas.

Participaram da pesquisa duas estudantes identificadas com AH/SD: Alice, de 11 anos, e Tóquio de 12 anos, cujos nomes são fictícios e foram escolhidos por elas. Ambas frequentavam o $6^{\circ}$ e $\circ 8^{\circ}$ ano, respectivamente, e a sala de recursos multifuncional para $\mathrm{AH} / \mathrm{SD}$, no contraturno escolar. A seleção dos dados dessas participantes, ocorreu devido ao fato de terem se destacado na temática discutida nesse artigo: a interação social para os estudantes que têm AH/SD. A técnica de coleta de dados foi a observação sistemática, cujo registro foi feito no diário de campo. O foco da observação foi identificar os comportamentos e atitudes das participantes da pesquisa. Esses registros foram feitos após cada encontro de intervenção.

Também foi utilizado um instrumento elaborado pelas pesquisadoras, composto por histórias cujo conteúdo tinha relação com conflitos sociopedagógicos, seguidas de perguntas desafiadoras a respeito da situação. A esse instrumento, foi atribuído o nome de cadernos de conflitos. Um conflito foi apresentado no formato de $\mathrm{HQ}$ (História em Quadrinhos) e outro em formato de texto. Essa diferença na apresentação se justifica pela necessidade de variação na apresentação do instrumento, a fim de estimular o envolvimento dos participantes na pesquisa.

O procedimento de registro das respostas teve como objetivo identificar quais seriam as atitudes das participantes da pesquisa, supondo que a situação ocorresse com elas. Após os registros das respostas, a pesquisadora convidava as participantes a compartilhar as suas respostas para que pudessem conhecer e refletir sobre o ponto de vista dos demais, promovendo assim a interação entre elas.

O primeiro conflito foi apresentado no formato de $\mathrm{HQ}$ e apresentou a seguinte história: $\mathrm{Na}$ aula de Educação Física, do $7^{\circ} \mathrm{X}$, a professora Lucinda propôs várias atividades em grupos. Uma delas era o jogo cabo-de-guerra. Os grupos foram formados, mas o Nolan 
ficou de fora. Ninguém o quis no seu grupo porque ele não tinha força e sempre perdia nas competições.

A partir da história, foram desafiados a responder as seguintes questões: A) O que você pensa sobre a atitudes dos colegas em relação a não ter escolhido o menino? B) $O$ que você faria se estivesse nessa turma? C) Se você fosse a professora da turma, o que você faria?

Figura 1 - Primeiro Conflito Sociopedagógico
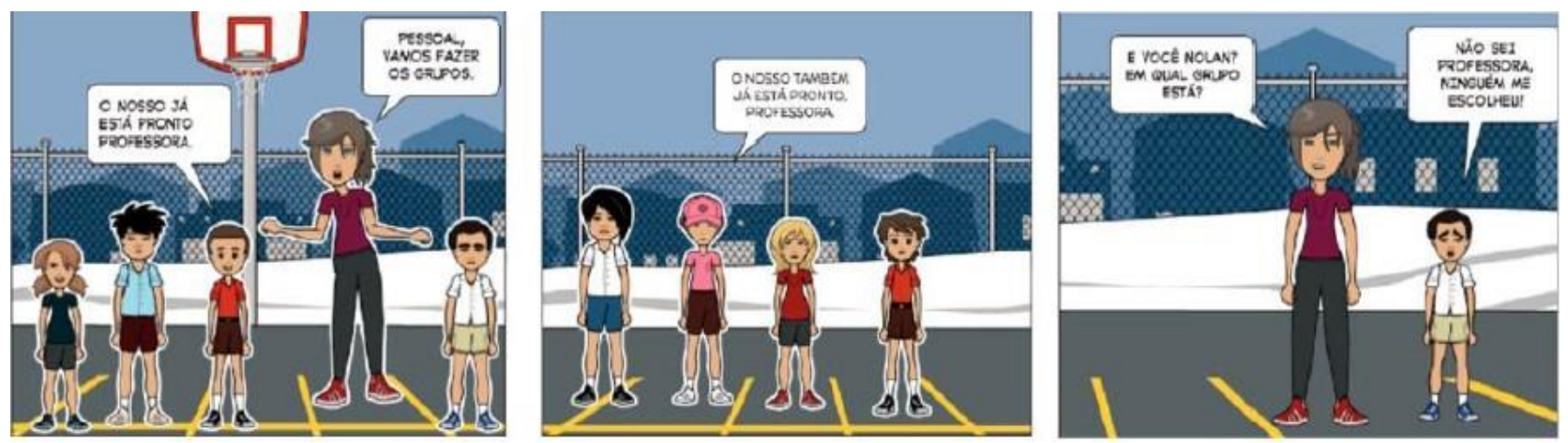

Fonte: Elaborado pelas autoras, utilizando a ferramenta Pixton, disponível em: www.pixton.com.

O segundo conflito sociopedagógico foi apresentado somente com texto, e trouxe a seguinte situação: No $8^{\circ} \mathrm{M}$, havia uma estudante nova na escola e que veio transferida de Santa Catarina. Pâmela era muito tímida, conversava pouco, e os colegas não a incluíam nas conversas. Na hora do recreio também estava sempre sozinha. $\mathrm{Na}$ sala de aula, quando ocorria trabalho em grupo, ela não era escolhida.

A partir dessa situação, foram feitos alguns questionamentos: A) Você acha correta essa atitude dos colegas? B) Se você estudasse nessa turma, o que você faria? C) Se você fosse o professor, o que faria?

$\mathrm{Na}$ perspectiva dessa pesquisa, os conflitos sociopedagógicos acontecem em qualquer situação que comumente ocorrem na escola, nas quais estão envolvidos estudantes ou professores, e que desencadeie uma discussão, discordâncias ou críticas.

Dessa forma, foram apresentadas histórias elaboradas pelas pesquisadoras, contendo suposições de conflitos que comumente acontecem em sala de aula.

A metodologia de análise dos dados foi inspirada no Método Clínico, pois os conflitos sociopedagógicos foram analisados em cada resposta dada. 
http://dx.doi.org/10.5902/1984686X67108

\section{Resultados e discussões}

O encaminhamento metodológico para cada encontro foi realizado da seguinte forma: em um primeiro momento, a pesquisadora procedeu a exposição oral dos conflitos sociopedagógicos, e em seguida fez questionamentos sobre a compreensão das histórias desses conflitos. Após essa interação, os estudantes foram convidados a elaborar uma resposta por escrito, no instrumento de pesquisa elaborado pelas pesquisadoras, ou seja, o caderno de conflitos sociopedagógicos. Após a escrita, as respostas foram compartilhadas e discutidas no coletivo, entre pesquisadora e participantes. Como dito anteriormente, como esse trabalho é um recorte da tese, a pesquisa foi realizada na sala de recursos multifuncional para $\mathrm{AH} / \mathrm{SD}$, onde havia mais cinco estudantes.

No quadro, estão postas as principais respostas de Alice e Tóquio, ao conflito sociopedagógico 1.

Quadro 1 - Conflito Sociopedagógico 1

\begin{tabular}{|l|l|l|l|}
\hline Participante & \multicolumn{1}{|c|}{ A } & \multicolumn{1}{c|}{ B } & \multicolumn{1}{c|}{ C } \\
\hline Alice & $\begin{array}{l}\text { Acho egoísta pois eles } \\
\text { poderiam ter chamado } \\
\text { Nolan. }\end{array}$ & $\begin{array}{l}\text { Chamaria Nolan pois não } \\
\text { queria que ele ficasse } \\
\text { sozinho. }\end{array}$ & $\begin{array}{l}\text { Colocaria em um grupo } \\
\text { pois não ficaria sozinho. }\end{array}$ \\
\hline Tóquio & $\begin{array}{l}\text { Acho que forma não só } \\
\text { sem educação mas } \\
\text { também infantil e egoísta } \\
\text { pois todos sem exceção } \\
\text { devem participar para } \\
\text { poder compartilhar. } \\
\text { A vida é assim, nem } \\
\text { sempre as coisas } \\
\text { acontecem do jeito que } \\
\text { esperamos, temos que } \\
\text { aprender com isso. }\end{array}$ & $\begin{array}{l}\text { Tentaria me entrosa no } \\
\text { grupo pois eles podem já ter } \\
\text { uma opinião formada sobre } \\
\text { mim. }\end{array}$ & $\begin{array}{l}\text { Colocaria em um grupo, } \\
\text { brigaria com a turma. }\end{array}$ \\
\hline
\end{tabular}

Fonte: Valentim (2019).

Após a discussão coletiva desse conflito sociopedagógico, a pesquisadora os desafiou a escolher uma palavra que pudesse resumir o fato analisado. As palavras escolhidas foram: egoísmo e vida. Palavras que os levaram a descentração do pensamento, se colocando no lugar dos personagens da história, e refletindo sobre o que aconteceu também com eles na escola.

Constatou-se que os participantes não concordaram com situações de exclusão. Nas suas respostas, se colocaram no lugar da professora e pensaram em uma solução para 
http://dx.doi.org/10.5902/1984686X67108

promover a participação do colega. Ao se colocarem na posição de colegas do menino, revelaram que o chamariam para participar do seu grupo ou pediriam para a professora fazer isso. Demonstraram ser solidários e que teriam atitudes de cooperação e tentativas de interação no grupo. É o que demonstraram as participantes: "Chamaria o menino, pois não queria que ele ficasse sozinho". (ALICE). E ainda, "Todos, sem exceção, devem participar para poder compartilhar". (TÓQUIO).

Igualmente, chamou a atenção o fato de definirem a atitude dos colegas como bullying e, ao mesmo tempo, se identificaram com o personagem da história, por já terem vivenciado situação semelhante. No momento de compartilhamento das respostas, foi possível perceber que essa situação era citada pelas duas participantes.

Ao mesmo tempo em que se mostraram indignadas, também deixaram transparecer certa conformidade, quando resumiram que isso acontece na vida, mas que é preciso aprender com a situação e reagir diante das dificuldades. A exemplo, cita-se o exposto por Tóquio: "A vida é assim, porque nem sempre as coisas acontecem do jeito que esperamos e temos que aprender com isso". Alice se mostrou inconformada quando relatou que "Chamaria Nolan, pois não queria que ele ficasse sozinho".

Durante o compartilhamento e discussão das respostas, Tóquio relata que gosta de falar sobre os conflitos e gosta de debater com os professores. No entanto, percebe que isso os "chateia", e que por vezes, não respondem às suas dúvidas (TÓQUIO). Nesse momento, a pesquisadora intervém e questiona os demais sobre como poderiam ajudar a Tóquio. Alice responde que é importante que ela continue perguntando e tentando o diálogo com seus professores.

Assim, observou-se que Alice e Tóquio procuraram interagir e demonstraram disposição para dialogar e discutir. Percebe-se que os estudantes com AH/SD, fariam um grande esforço para incluir o menino no grupo e não se conformaram com situações de isolamento e de exclusão. Demonstraram em seus julgamentos que valorizam a participação coletiva, bem como a cooperação e interação entre os estudantes.

A troca de ideias sobre o problema apresentado foi enriquecedora para elaborações verbais de soluções. Pensar sobre os conflitos é uma forma de desenvolver criticidade e tomada de decisões, bem como de antecipar atitudes quando elas acontecem em situações reais.

Esses resultados corroboram os resultados da pesquisa de Valentim e Vestena (2019, p. 16): 
http://dx.doi.org/10.5902/1984686X67108

É preciso compreender que precisamos uns dos outros para nos afirmar como cidadãos críticos, aqueles tão almejados pelos projetos políticos pedagógicos das instituições escolares. A discussão verbal de problemas reais é um caminho para conseguir alcançar esse objetivo, já que desentendimentos entre os alunos e com professores são comuns acontecerem na escola. Precisamos aproveitar estes acontecimentos para refletir sobre as ações e busca de alternativas.

Dar importância para esse movimento, significa dar oportunidade para desenvolver as relações interindividuais entre os estudantes com AH/SD. É uma forma de criar e fortalecer os laços afetivos entre eles e os colegas da escola.

No quadro 2, observa-se algumas respostas ao conflito sociopedagógico 2.

Quadro 2 - Conflito Sociopedagógico 2

\begin{tabular}{|l|l|l|l|}
\hline Participante & \multicolumn{1}{|c|}{ A } & \multicolumn{1}{c|}{ B } & \multicolumn{1}{c|}{ C } \\
\hline Alice & $\begin{array}{l}\text { Não, pois eles } \\
\text { tinham que acolher } \\
\text { ela para ela se sentir } \\
\text { bem. }\end{array}$ & $\begin{array}{l}\text { Fazer amizade com ela, pois queria } \\
\text { que ela se sentisse bem e com } \\
\text { vontade de fazer amigos. O } \\
\text { isolamento poderia causar uma } \\
\text { depressão. }\end{array}$ & $\begin{array}{l}\text { Falaria para os colegas } \\
\text { conversarem com ela } \\
\text { pois isso é o correto. }\end{array}$ \\
\hline Tóquio & $\begin{array}{l}\text { Acho uma injustiça } \\
\text { pois todos tem e } \\
\text { tiveram um primeiro } \\
\text { dia de aula. }\end{array}$ & $\begin{array}{l}\text { Fazer amizade em outra sala, pois lá } \\
\text { também poderia ter alguém sozinho. }\end{array}$ & $\begin{array}{l}\text { Comunicaria } \\
\text { autoridades do colégio } \\
\text { pois eles saberiam } \\
\text { resolver. }\end{array}$ \\
\hline
\end{tabular}

Fonte: Valentim (2019).

Os resultados da discussão desse conflito vão ao encontro dos resultados do primeiro. Nas respostas elaboradas, os participantes deixaram claro que não se conformariam com o isolamento da menina e buscariam sugerir formas de promover a interação dela no grupo de colegas. Demonstraram que se importariam em promover a interação dela na turma, ao mesmo tempo que tiveram interesse para aceitar novas pessoas em seu grupo. Confirmouse que não concordariam com a exclusão da menina nos grupos, e tomariam alguma atitude para promover a sua interação.

A discussão promovida a partir desse conflito também fez os estudantes se lembrarem dos seus próprios conflitos, bem como as formas possíveis de resolvê-los. Vale destacar que as questões analisadas pelos estudantes, sobre os conflitos sociopedagógicos, foram referentes aos personagens, porém, ao analisá-los, relacionaram consigo mesmos, fazendo comparações e se identificando com as situações vivenciadas por eles. Nesse sentido, a discussão promoveu uma descentração cognitiva, permitindo pensar no tempo 
http://dx.doi.org/10.5902/1984686X67108

presente e analisar o tempo passado, suas próprias vivências na escola. Constatou-se ainda, que houve interesse no envolvimento e interação com os colegas.

Ademais, as discussões realizadas no decorrer da pesquisa, por meio dos conflitos sociopedagógicos, promoveram o pensar sobre si e sobre as suas relações interindividuais.

Como se sabe, o envolvimento com a tarefa é um importante componente da Superdotação, pois ele envolve o investimento de tempo e energia para realizar determinadas tarefas. Por esse componente da Superdotação, podem ser identificados aqueles estudantes que se destacam na habilidade acima da média e na criatividade (RENZULLI, 2004, 2014). Desafiar o envolvimento, como a tarefa de interagir com as pessoas no círculo social de cada um, é tão importante quanto o envolvimento com uma atividade cognitiva, por exemplo.

A intervenção feita por meio da pesquisa, promoveu liberdade e autonomia para pensar e expressar o pensamento. Durante a realização da pesquisa, os estudantes com AH/SD liberaram suas vozes, e, são muitas vozes que precisam encontrar espaço para serem ouvidas. Fleith (2007) sugere que intervenções no âmbito da psicologia sejam feitas no sentido de "...desenvolver habilidades de resolução de conflitos, comunicação, liderança e tomada de decisão, desenvolver senso de humor e assertividade". Trabalhos dessa natureza também podem ser feitos no âmbito educacional e, certamente, essa é uma forma de dar voz e vez para estudantes com AH/SD.

Vale destacar que o método da pesquisa favoreceu a participação ativa também da pesquisadora, ao realizar as intervenções no momento da apresentação dos conflitos sociopedagógicos e do incentivo para que tivessem envolvimento com a tarefa de discussão dos conflitos sociopedagógicos nelas contidas. Ao envolverem-se na elaboração das respostas, houve também interação entre as participantes, o que afirma a resposta ao problema da pesquisa, ou seja, a resolução de conflitos sociopedagógicos pode promover a interação social em estudantes com AH/SD.

A interação entre os estudantes foi aumentando gradativamente, chegando a um momento em que foi preciso discutir entre eles uma forma de cada um ter a sua vez de falar. Isso demonstra a necessidade que eles têm de expor seus pontos de vista e, por outro lado, a importância de criar esse espaço de escuta e de interação.

Pode-se observar também, que a intervenção permitiu aos participantes da pesquisa fazer generalizações, formar esquemas, e construir estruturas de interação para desenvolver o envolvimento uns com os outros. A partir de vários esquemas são criadas as 
http://dx.doi.org/10.5902/1984686X67108

estruturas, que se configuram como um conjunto de esquemas fechados, porém são estruturas inacabadas, porque podem ser substituídas por outras (PIAGET, 2014).

No campo social, Piaget destacou a importância das relações entre os pares e as trocas sociais para construir ambientes cooperativos. Nesse processo, os conflitos cognitivo, social e moral são fundamentais, sendo necessário haver uma intervenção externa que provoque a mudança dessas estruturas (PIAGET, 1977a).

As discussões suscitaram a compreensão individual e coletiva dos conflitos, produzindo relações de novidades, que incluem a interação entre os pares e o compartilhamento de conflitos em comum.

Essas relações de novidade entre as pessoas com AH/SD, ocorrem no âmbito individual, mas também no coletivo. Becker e Marques (2012, p. 167) explicam que:

Não dependem de um processo de treinamento, mas dependem, sim, de interesse e de oportunidades para que o indivíduo tenha uma ampla gama de conteúdos sobre os quais aplicar suas estruturas, resultantes de abstrações reflexionantes previamente realizadas.

Interesse e oportunidade não se referem apenas aos conteúdos, mas nas relações que estão envolvidas nesse processo. Pela intervenção, os estudantes com AH/SD foram convidados a ultrapassar pontos de vista próprios, colocando-se no lugar dos outros, sendo mais solidários, empáticos e a pensar sob pontos de vista diferentes dos seus. Vale ressaltar que os participantes da pesquisa foram desafiados, em cada encontro, a continuar com reflexionamentos sobre as questões sociais que estão envolvidas nas relações interindividuais.

O envolvimento com a tarefa de fazer trocas uns com os outros por meio da interação social de qualidade, contribui para a cooperação. A reciprocidade dessas trocas, vai se construindo também na medida em que os conflitos decorrentes dessas relações tenham um espaço de valorização e de discussão, e que o isolamento - se vier a ocorrer - seja para os momentos de reflexionamentos no âmbito cognitivo, e não no âmbito social.

Outra questão, foi a novidade de participarem desse trabalho de pesquisa, pelo fato de termos proposto ao grupo uma forma para resolver conflitos ou, como foi batizado por um dos participantes, uma oficina de mediação de conflitos. Eles se envolveram, propuseram soluções, trocaram ideias e compartilharam esses pontos de vista. Pode-se dizer que mergulharam nas histórias e foram agentes ativos na busca de alternativas.

Vale destacar que os professores também podem ser agentes ativos para que a transformação aconteça no quesito do envolvimento com as pessoas, no convívio diário, 
http://dx.doi.org/10.5902/1984686X67108

assim como a pesquisadora foi com as participantes da pesquisa. Eles podem intervir nos conflitos sociopedagógicos favorecendo o ambiente colaborativo e construtivo, contribuindo para a compreensão da importância de si e do outro, criando, dessa forma, espaços para fortalecimento das relações interindividuais e do pertencimento de grupo.

O ambiente colaborativo e construtivo não se faz automaticamente, ele é desenvolvido a partir das relações de reciprocidade entre estudantes com AH/SD e os seus professores. Para isso, é importante que os professores desenvolvam essa perspectiva de trabalho. É preciso planejar ações que corroborem essa finalidade. Nas palavras de Valentim e Vestena (2019, p. 17):

A organização do trabalho pedagógico flexível, que busca favorecer o desenvolvimento da moral autônoma dos estudantes com AH/SD colabora para a construção de um ambiente escolar favorável ao diálogo, respeito mútuo e cooperação, o que garante, assim, a valorização do senso crítico.

O papel de professoras é muito importante, mas eles também precisam de apoio para organizar o trabalho pedagógico com estudantes que têm AH/SD. Também precisam de espaço e tempo para repensar e valorizar a sua identidade enquanto profissionais da educação. Na formação de professores, tanto inicial quanto continuidade, se faz urgente incluir a discussão da dimensão social desse público-alvo da Educação Especial.

Corroborando Carbone e Menin (2004), destaca-se que professores com alto nível de desenvolvimento moral, elevam o nível de desenvolvimento moral de seus estudantes. Disso decorre a importância de formação continuada aos professores para saber trabalhar com as pessoas com AH/SD e com o desenvolvimento moral, pois professores devem ser agentes que intervém para a autonomia dos estudantes. Dessa forma, se constroem relações recíprocas entre todos no espaço da sala de aula e da escola, como um todo.

Para Piaget (2014, p. 96), “A reciprocidade não é uma troca 'generoso-generoso', mas um enriquecimento mútuo de parceiros pela troca de atitudes". Sendo assim, com o respeito mútuo, se constrói as relações num sistema de valorização de ambas as partes, professores e estudantes com AH/SD rumo a autonomia moral.

A reciprocidade desenvolvida entre a pesquisadora e os participantes, demonstra a urgência dessa troca social a fim de que os conflitos sejam valorizados e aproveitados no contexto educacional, para promoção da interação social de qualidade. Assim como o método de pesquisa favoreceu essa troca entre pesquisadora e participantes, há que se pensar no papel central dos professores de usar os conflitos para promover os espaços de reciprocidade. 
http://dx.doi.org/10.5902/1984686X67108

Destaca-se, ainda, "Ora, sem relação com outrem, não há necessidade moral: o indivíduo como tal conhece apenas a anomia e não a autonomia". (PIAGET, 1977a, p. 110). Essa relação é de extrema importância para promover o envolvimento com a tarefa de interação social. Importar-se com o outro, tem sido uma importante habilidade a ser desenvolvida e praticada.

\section{Contribuições para a Educação Especial}

Este estudo trouxe contribuições educacionais relevantes, particularmente para estudantes com AH/SD. Sabe-se que essa é a parcela menos estudada do público-alvo da Educação Especial, e ainda vale ressaltar que, dos estudos sobre AH/SD, a dimensão menos estudada é a social.

Os resultados oriundos dessa pesquisa, chamam a atenção para a urgência de discutir os conflitos sociopedagógicos que surgem no contexto escolar, colocando-os em lugar de destaque nos encaminhamentos das aulas. Dar importância para os conflitos proporciona momentos de discussão e busca de alternativas que promovam ambiente cooperativo a partir do olhar atencioso ao ponto de vista daqueles que convivem no espaço escolar.

Uma forma de dar destaque aos conflitos, é utilizá-los para a promoção da interação social, e isso perpassa inicialmente pela postura do professor em sala de aula. Ou seja, conflitos não podem ser calados, eles precisam ser considerados e discutidos no coletivo para buscar formas de resolução. É preciso dar atenção para as perguntas, para as dúvidas, para as contribuições que os estudantes com AH/SD têm a dar aos seus pares.

Nessa perspectiva, aponta-se para duas formas de trabalhar com os conflitos sociopedagógicos. Uma é criando uma proposta de enriquecimento extracurricular, que tenha como foco a discussão de conflitos - assim como foi a proposta dessa pesquisa. A outra, é aproveitar os conflitos que surgem na sala de aula comum, ou na sala de recursos multifuncional, para discutir com os estudantes a melhor forma de resolvê-los. Se assim for, ambientes cooperativos serão construídos na escola e isso não será benefício apenas para os estudantes com $\mathrm{AH} / \mathrm{SD}$, mas para toda a escola.

Saber lidar com conflitos é uma habilidade fundamental para a convivência na escola. Quando se organizam ações pedagógicas dessa natureza, aos poucos vai se construindo um ambiente saudável social e emocionalmente para que todos possam conviver de forma colaborativa na escola. Dessa forma, a noção de pertencimento, algo inerente e necessário 
http://dx.doi.org/10.5902/1984686X67108

em uma escola inclusiva, vai se constituindo, e os estudantes com AH/SD podem se reconhecer como parte desse espaço e compreender que a riqueza da diversidade humana é ter pontos de vista diferenciados e que podemos conviver e aprender com isso, de forma democrática.

Assim como nessa pesquisa foi criado um instrumento, denominado de caderno de conflitos, para que os estudantes pudessem registrar seus pontos de vista para refletir coletivamente sobre eles, pode-se fazer isso também nas salas de aula comum e na sala de recursos multifuncional.

Uma opção a ser considerada para esses espaços, é a construção de um dossiê, um caderno ou um livro ilustrado de conflitos. Considerando o potencial criativo dos estudantes com AH/SD, essa opção pode ser ampliada a partir das suas próprias sugestões. A construção coletiva desse material poderá promover com mais qualidade a interação, 0 envolvimento uns com os outros, a criação e o fortalecimento de vínculo, bem como a noção de pertencimento.

\section{Conclusões}

Com o aumento de pesquisas que abordam a Superdotação, reafirma-se o reconhecimento de que as pessoas com essas características fazem parte do público-alvo da Educação Especial e, portanto, têm direito ao AEE, que deve ser organizado de modo a contemplar todas as áreas de desenvolvimento, inclusive a social. Há que se perceber, no entanto, que a interação social tem sido a temática menos pesquisada.

Apesar da lacuna constatada nas pesquisas, é importante mencionar que têm contribuído para que os estudantes com AH/SD não permaneçam invisíveis na escola e na sociedade. O progresso nas pesquisas tem contribuído para que sejam garantidos os direitos ao atendimento educacional especializado, tanto em nível nacional, quanto internacional. A insuficiência se refere, então, a estudos para um melhor desenvolvimento de atividades visando a interação social.

Nessa pesquisa, foram apresentados resultados que corroboram a importância e a necessidade de desenvolver práticas pedagógicas que promovam a interação social entre os estudantes com AH/SD. Os resultados demonstraram que, a discussão de conflitos sociopedagógicos promoveu o envolvimento, a interação e a cooperação entre os estudantes. Demonstrou também, que é preciso dar atenção às perguntas, às dúvidas e às contribuições que os estudantes com AH/SD têm vontade de fazer na sala de aula. 
A discussão dos conflitos sociopedagógicos no contexto escolar entre professores e estudantes, também favorece a autonomia moral nos estudantes, quando esta relação está pautada no respeito mútuo, nas relações de cooperação e de interação social de qualidade entre eles. Com a discussão dos conflitos que surgem nas mais diversas situações de sala de aula, há também a oportunidade de interação entre os professores e entre os colegas.

Com o presente estudo, destaca-se a importância de que os estudantes com AH/SD devem ser agentes ativos, trazendo os seus conflitos para serem discutidos em sala de aula. Para isso, é necessário criar na escola um ambiente construtivista para os conflitos sociopedagógicos, pois precisam desse espaço. De nada adiantará trazer seus conflitos e não ter oportunidade de falar sobre eles.

Nesse movimento, os próprios estudantes devem antecipar formas cooperativas, pois conflitos podem surgir inesperadamente, mas a ação para a resolução pode ser pensada antes mesmo que ele ocorra. Sabe-se que nesse movimento de resolução de conflitos, pequenas ações são responsáveis por grandes mudanças, por isso é preciso desafiar os estudantes para que esquemas sejam criados onde essas mudanças se tornem cada vez mais ativas.

Uma proposta prática que pode ser implementada, é o enriquecimento extracurricular para a escola toda, com base na discussão de conflitos sociopedagógicos. Cada professor, na sua disciplina, pode usar os conflitos que acontecem em suas aulas para enriquecer seu conteúdo e o envolvimento entre os estudantes. É assim que se constrói uma forma de conhecer melhor os colegas que convivem na escola, e fortalecer a interação social entre eles.

A partir dos resultados dessa pesquisa, conclui-se que a ação no âmbito da discussão coletiva, exerce importante papel para construir níveis mais elaborados da compreensão de si e do outro, desde que o envolvimento, a cooperação, a interação, e o conflito, estejam presentes nas relações interindividuais. Ademais, a discussão de conflitos sociopedagógicos pode promover a interação social em estudantes com AH/SD.

Destaca-se que a interação social de qualidade foi elemento central na intervenção para os envolvidos na presente pesquisa. Aponta-se, igualmente, que a pesquisa de intervenção representa uma importante contribuição, não somente para o desenvolvimento e produção do conhecimento científico, mas também como um caminho para transformar realidades que se cristalizaram ao longo da história da educação escolar, das pessoas com AH/SD. 
http://dx.doi.org/10.5902/1984686X67108

\section{Referências}

BECKER, Fernando; MARQUES, Tania Beatriz Iwasko. Epistemologia genética e criança superdotada. In: MOREIRA, Laura. Ceretta.; STOLTZ, Tania. (Coords.). Altas habilidades/superdotação, talento, dotação e educação. Curitiba, PR: Juruá, 2012.

BRASIL. Ministério da Educação. Secretaria de Educação Especial. Marcos políticolegais da educação especial na perspectiva da educação inclusiva. Brasília, DF: Secretaria de Educação Especial. 2010. 73p. Disponível em: http://portal.mec.gov.br/index.php?option=com_docman\&view=download\&alias=6726 marcos-politicos-legais\&Itemid=30192 Acesso em: 19 set. 2021.

CARBONE, Renata Aparecida; MENIN, Maria Suzana de Estéfano. Injustiça na escola: representações sociais de alunos do ensino fundamental e médio. Educação e Pesquisa, São Paulo, v. 30, n. 2, p. 251-270, maio/ago. 2004. Disponível em https://www.redalyc.org/pdf/298/29830204.pdf. Acesso em: 8 ago. 2021.

FLEITH, Denise de Souza. Altas habilidades e desenvolvimento socioemocional. In.: FLEITH, Denise de Souza; ALENCAR, Eunice M. L. Soriano de. Desenvolvimento de talentos e altas habilidades: orientação a pais e professores (Orgs.) Porto Alegre: Artmed, 2007.

GERHARDT, Tatiana Engel; SILVEIRA, Denise Tolfo (orgs.) Métodos de Pesquisa. Porto Alegre: Editora da UFRGS, 2009, 120 p.

HEUSER, Brian L.; WANG, Ke; SHAHID, Salman. Global dimensions of gifted and talented education: the influence of national perceptions on policies and practices. Global Education Review, v. 4, n. 1, p. 4-21, 2017. Disponível em:

https://files.eric.ed.gov/fulltext/EJ1137994.pdf. Acesso em: 7 jan. 2019.

MARTINS Bárbara Amaral. et al. Altas habilidades/superdotação: estudos no Brasil. Journal of Research in Special Education Needs, v. 16, n. 1, p. 135-139, 2016. Disponível em: https://nasenjournals.onlinelibrary.wiley.com/doi/epdf/10.1111/1471 3802.12275 Acesso em: 7 jan. 2019.

MARTINS, Bárbara Amaral; CHACON, Miguel Claudio Moriel; ALMEIDA, Leandro Da Silva. Estudo comparativo luso-brasileiro sobre a formação inicial de professores em altas habilidades/superdotação com enfoque nos conteúdos curriculares. Revista Brasileira Educação Especial, Marília, SP, v. 24, n. 3, p. 309-326, jul./set. 2018. Disponível em: http://www.scielo. br/. Acesso em: 7 jan. 2019.

MCCLAIN, Mary-Catherine; PFEIFFER. Steven. Identificacion of gifted studets in the United States today: a look at state definitions, policies, and practices. Journal of Applied Scholl Psychology, v. 28, n. 1, p. 59-88, 2012. Disponível em:

https://www.academia.edu/. Acesso em: 23 jan. 2017.

NAKANO, Tatiane de Cássia; SIQUEIRA, Luciana Gurgel Guida. Revisão de publicações periódicas brasileiras sobre superdotação. Revista de Educação Especial, Santa Maria, v. 25, n. 43, p. 249-266, 2012. Disponível em:

https://periodicos.ufsm.br/educacaoespecial/article/view/3615 Acesso em: 20 jan. 2021. 
PÉREZ, Suzana Graciela Pérez Barrera; FREITAS, Soraia Napoleão. Encaminhamentos pedagógicos com alunos com altas habilidades/superdotação na educação básica: o cenário brasileiro. Educar em Revista, Curitiba/PR, n. 41, p. 109-124, 2011. Disponível em: https://www.scielo.br/j/er/a/hv87YLFWx6BGY7C8JCNqWjP/abstract/?lang=pt Acesso em: 10 jan. 2021.

PIAGET, Jean. O julgamento moral na criança. Tradução Élzon Lenardon. São Paulo: Mestre Jou, 1932/1977a.

PIAGET, Jean. A tomada de consciência. São Paulo: Melhoramentos, 1977b.

PIAGET, Jean. Relações entre a afetividade e a inteligência no desenvolvimento mental da criança. Tradução Cláudio J. P. Saltini e Doralice B. Cavenaghi. Rio de Janeiro: Wak Editora, 1962/2014.

RENZULLI, Joseph Salvatore. O que é esta coisa chamada superdotação, e como a desenvolvemos? Uma retrospectiva de vinte e cinco anos. Educação, v. 27, n. 52, p. 75131, 2004. Disponível em: https://www.redalyc.org/pdf/848/84805205.pdf Acesso em: 10 jan. 2021.

RENZULLI, Joseph Salvatore. A concepção de superdotação no modelo dos três anéis: um modelo de desenvolvimento para a promoção da produtividade criativa. In: VIRGOLIM, Ângela Mágda Rodrigues; KONKIEWITZ, Elisabete Castelon. Altas habilidades/superdotação, inteligência e criatividade: uma visão multidisciplinar. Campinas, SP: Papirus, 2014.

ROCHA, Maria Lopes Da; AGUIAR, Kátia Faria De. Pesquisa-intervenção e a produção de novas análises. Psicologia Ciência e Profissão, v. 23, n.4, p. 64-73, 2003. Disponível em: http://pepsic.bvsalud.org/pdf/pcp/v23n4/v23n4a10.pdf. Acesso em 13 set. 2019.

SUMIDA, Manabu. Emerging trends in Japan in education of the gifted: a focus on science education. Journal for the Education of the Gifted, v. 36, n. 3, p. 277-289, 2013. Disponível em: http://journals.sagepub.com. Acesso em: 23 jan. 2017.

TRIVIÑOS, Augusto Nibaldo Silva. Introdução à pesquisa em Ciências Sociais: a pesquisa qualitativa em educação. São Paulo: Atlas, 2011.

VALENTIM, Bernadete Fatima Bastos. Estudantes com altas

habilidades/superdotação: uma proposta de intervenção com base em conflitos sociopedagógicos. 2019. 237f. Tese (Doutorado em Educação) - Universidade Federal do Paraná. Setor de Educação, Programa de Pós-Graduação em Educação, Curitiba, 2019.

VALENTIM, Bernadete Fatima Bastos.; VESTENA, Carla Luciane Blum. Análise da noção de justiça em estudantes com altas habilidades/superdotação: uma contribuição educacional. Revista de Educação Especial de Santa Maria, v. 32, p. 1-21, 2019. Disponível em: https://periodicos.ufsm.br/educacaoespecial/article/view/20149. Acesso em: 4 ago. 2021.

VINHA, Telma Pileggi. Os conflitos interpessoais na escola. In: GARCIA, Joe; TOGNETTA, Luciene Regina Paulino; VINHA, Telma Pileggi. Indisciplina, conflitos e bullying na escola. Campinas, SP: Mercado das Letras, 2013. 
VIRGOLIM, Angela. Altas habilidades/superdotação: um diálogo pedagógico urgente. Curitiba: Editora Intersaberes, 2019.

(c) (1) (3) International (CC BY-NC 4.0) 